\title{
Associations of sleep quality, quantity and nutrition in oldest-old men The Helsinki Businessmen Study (HBS)
}

\author{
Satu K. Jyväkorpi ${ }^{1}$ (D) Annele Urtamo ${ }^{1} \cdot$ Mika Kivimäki $^{1} \cdot$ Timo E. Strandberg $^{1,2}$
}

Received: 29 June 2020 / Accepted: 14 October 2020 / Published online: 1 November 2020

(c) The Author(s) 2020

\section{Key summary points}

Aim To investigate associations of sleep quality and quantity and nutrition in oldest-old men.

Findings Sleep quality was associated with nutritional status and vegetable intakes, whereas sleep quantity was linked to fish intake.

Message Healthy nutrition may be an important contributor of sleep hygiene in oldest-old men.

\begin{abstract}
Introduction Sleep quality and quantity often decline as people age, which may negatively impact health. We examined how nutrition is associated with self-reported sleep quality and quantity in oldest-old community-dwelling men.

Methods In this cross-sectional analysis of the Helsinki Businessmen Study (HBS), a random sample of 130 surviving participants underwent a clinical examination in 2017-2018. Food and nutrient intakes were retrieved from 3-day food diaries in 126 men, and sleep quality and quantity were determined with a questionnaire. Nutritional status was assessed using Mini Nutritional Assessment Short Form (MNA-SF), General Health and Vitality were measured with RAND-36/SF-36 healthrelated quality of life instrument, and albumin and creatinine levels were analyzed from fasting serum samples.

Results Mean age of the survivors was 87 years (range 83-99). Self-reported sleep quality and quantity were highly correlated $\left(p<0.001, \eta^{2}=0.693\right)$. Nutritional status (MNA-SF) $\left(p=0.006, \eta^{2}=0.076\right)$, vegetable intake $\left(p=0.030 . \eta^{2}=0.041\right)$ and vitality $\left(p=0.008, \eta^{2}=0.101\right)$ were associated with better sleep quality and fish $\left(p=0.028, \eta^{2}=0.051\right)$ intake was associated with longer sleep duration. This association remained after adjusting for age, sleep quality, carbohydrate energy $\%$, and albumin levels.

Conclusion Healthy nutrition may be an important contributor to sleep hygiene in oldest-old men.
\end{abstract}

Keywords Sleep quality $\cdot$ Sleep quantity $\cdot$ Nutritional status $\cdot$ Vegetable intake $\cdot$ Fish intake $\cdot$ Oldest-old men

\section{Introduction}

Sleep is a biologic process that is essential for brain function and human physiology including metabolism, appetite regulation, immunity as well as hormonal and cardiovascular systems [1]. Normal sleep may be defined as having sufficient quantity, good quality, and lacking sleep disturbances

Satu K. Jyväkorpi

satu.jyvakorpi@gery.fi

1 Helsinki University Hospital, Clinicum, University of Helsinki, Helsinki, Finland

2 Center for Life Course Health Research, University of Oulu, Oulu, Finland and disorders [2]. Sleep quality and quantity often decline as people age [3], but how much this is due to intrinsic or extrinsic factors, such as lifestyle, is unclear in very old age.

Nutrition and sleep have been studied in cross-sectional, longitudinal and experimental studies [4-8]. Healthy dietary patterns characterized by abundant intake of fruits, vegetables and legumes have been associated with better sleep quality and less sleep disturbances [5, 6]. Intakes of specific foods, such as fatty fish [7], kiwi fruit [4], and tart-cherry juice [9], and of nutrients (e.g., complex carbohydrates and vitamin D) [8] have also been associated with better sleep in adults. In older people greater dietary diversity $[10,11]$ and appetite [10] have been linked to better sleep. However, although oldest-old people are a risk group for poor sleep [3], studies on nutrition and sleep among them are 
very scarce [12]. Therefore, we sought to identify nutritionrelated factors that are associated with sleep quality and quantity in oldest-old community-dwelling men.

\section{Participants and methods}

In the Helsinki Businessmen Study (HBS), a socioeconomically homogenous cohort of men-born between 1919 and 1934-has been followed up since the 1960s [13]. From 600 survivors in 2017-2018, a random sub-cohort of 180 homeliving men were invited to participate in the clinic visit and 130 men attended (mean age 87 years, range 83-99 years). The main reasons for refusals were poor health, cognitive disorders disease or institutionalization. Examinations included body mass index [BMI, calculated as weight $(\mathrm{kg}) /$ height (m) squared], nutritional status using Mini Nutritional Assessment Short form (MNA-SF) [14], and 12-h fasting serum samples analyzed for a variety of parameters at the routine laboratory of the Helsinki University hospital. Although MNA has not been formally validated in Finland, it is widely used as a translation (Nestle...) in Finnish health care. Subjective health and vitality were assessed using scores in appropriate scales (General Health, Vitality) of the RAND-36/SF-36 Health-Related Quality of Life (HRQoL) instrument $[15,16]$. Food intakes were retrieved from 3-day food diaries, which a nutritionist checked, verified and asked for clarifications if necessary. The participants were asked about their sleep quality with a question "In your opinion would you classify your sleep quality to be good, average, or poor?". They were also asked how many hours per night and day they slept. Total diurnal sleeping time was categorized into three groups; $<7,7-9$ and $>9 \mathrm{~h}$ of sleep.

We evaluated trend and statistical significance of linearity for both sleep quality and total sleep time using ANOVA for continuous variables, and Cochran Armitage test of categorical variables. Strength of association was calculated using eta square. In addition, we used analysis of covariance (ANCOVA) to investigate independent associations with sleeping time. Covariates were selected based on ANOVA trend analysis and prior research $[7,17,18]$ and included age, sleep quality, serum albumin, serum creatinine, fish intake, and carbohydrate energy \% of total energy. Statistical analyses were performed using the SPSS statistical program, version 24 (SPSS IBM, Armonk, NY, USA).

\section{Ethics}

All participants signed an informed consent and the study protocol was approved by the Ethics Committee of the Helsinki University Hospital, Department of Medicine.
The study is registered with ClinicalTrials.gov identifier: NCT02526082.

\section{Results}

Of the 130 participants who attended the clinic, 126 returned food diaries. Of them, 27\% ( $n=36), 58 \%(n=75)$, and $15 \%$ $(n=22)$ reported having good, average or poor sleep quality, respectively (Table 1). Self-reported sleep quality correlated with total sleeping time $\left(p<0.001, \eta^{2}=0.693\right)$. Sleep quality showed a linear trend with MNA-SF-assessed nutritional status $\left(p=0.006, \eta^{2}=0.076\right)$ and Vitality score of the RAND-36 $\left(p=0.008, \eta^{2}=0.101\right)$, whereas no significant association was observed with BMI, General Health score of the RAND-36, serum albumin or creatinine levels. Of food intakes, vegetable intake showed a linear trend with higher sleep quality $\left(p=0.030, \eta^{2}=0.041\right)$. Higher intake of sugars showed a non-significant trend for poor sleep quality $\left(p=0.050, \eta^{2}=0.052\right)$. A similar, non-significant trend for poor sleep was observed with higher saturated fatty acid (SFA) $\left(p=0.058, \eta^{2}=0.035\right)$ intake. Other food intakes were not related to sleep quality.

For sleep duration, $32 \%,(n=42), 51 \%(n=67)$, and $17 \%$ $(n=22)$ of the participants reported sleeping $\leq 7 \mathrm{~h},>7 \leq 9 \mathrm{~h}$, and $>9 \mathrm{~h}$ during night time, respectively (Table 2). Sleeping longer at night was associated with better sleep quality $(p<0.001)$ and higher fish intake $\left(p=0.028, \eta^{2}=0.051\right)$. Other food intakes were not associated with sleep duration. BMI, General Health and Vitality scores of RAND-36, serum albumin and creatinine levels, and other food intakes were not associated with sleep quantity either.

In multivariate analyses, sleep duration was associated with sleep quality and fish intake after adjustment for age, albumin level and carbohydrate energy \% intake (Table 3).

\section{Discussion}

In men at age of 83-99 years, sleep quality was associated with nutritional status and vegetable intakes, whereas sleep duration was linked to higher fish consumption. These findings are consistent with the hypothesis that healthy nutrition may contribute to good sleep also in the oldest-old men.

Previous studies have suggested that both sleeping too little or too much a day may be associated with adverse health outcomes [19]. In our study, scores in the General Health and Vitality scales of the RAND-36 instrument were not related to the amount of reported sleep, whereas sleep quality was associated with Vitality scores. Sleep quality and quantity typically decline as people age [3]. Although it is 
Table 1 Characteristics and food intakes according to self-reported sleep quality of the oldest-old men

\begin{tabular}{|c|c|c|c|c|c|}
\hline \multirow[t]{2}{*}{ Characteristics } & \multicolumn{5}{|c|}{ Self-reported sleep quality } \\
\hline & Good $(n=36)$ & Average $(n=76)$ & Poor $(n=19)$ & $p$ value $^{1}$ & $\eta^{2}$ \\
\hline Age, years & $87.0(2.6)$ & $87.5(3.0)$ & $87.4(3.1)$ & 0.488 & 0.006 \\
\hline Total sleep time, $\mathrm{h}$ & $8.6(1.3)$ & $8.2(1.6)$ & $6.8(1.5)$ & $<0.001$ & 0.693 \\
\hline MNA-SF, points & $13.3(0.9)$ & $13.1(1.0)$ & $12.2(2.2)$ & 0.006 & 0.076 \\
\hline $\mathrm{BMI} \mathrm{kg} / \mathrm{m}^{2}$ & $25.9(2.4)$ & $26.2(2.7)$ & $24.4(3.0)$ & 0.151 & 0.051 \\
\hline Albumin, mmol/L & $37.5(2.9)$ & $38.0(3.4)$ & $37.5(1.6)$ & 0.872 & 0.007 \\
\hline Creatinine, $\mathrm{mmol} / \mathrm{L}$ & $95(25)$ & $111(63)$ & $102(36)$ & 0.397 & 0.019 \\
\hline General Health, RAND-36, 0-100 points & $58(16)$ & $60(16)$ & 49 (18) & 0.151 & 0.052 \\
\hline Vitality, RAND-36, 0-100 points & $68(21)$ & $68(17)$ & $50(23)$ & 0.008 & 0.101 \\
\hline \multicolumn{6}{|l|}{ Food intakes, g/day } \\
\hline Vegetables & $184.5(150.3)$ & $157.2(132.8)$ & $97.0(58.7)$ & 0.030 & 0.041 \\
\hline Fruits and berries & $147.8(195.6)$ & $148.0(144.1)$ & $115.2(160.2)$ & 0.565 & 0.005 \\
\hline Nuts & $2.9(6.5)$ & $6.4(18.6)$ & $3.1(9.1)$ & 0.736 & 0.012 \\
\hline Legumes & $5.4(18.0)$ & $7.6(21.1)$ & $5.6(12.0)$ & 0.861 & 0.003 \\
\hline Fish & $61.9(63.2)$ & $63.7(57.8)$ & $60.3(52.7)$ & 0.974 & 0.000 \\
\hline Meat & $97.5(47.1)$ & $106.8(63.2)$ & $103.4(47.8)$ & 0.608 & 0.005 \\
\hline Egg & $16.2(28.9)$ & $16.8(26.5)$ & $15.7(35.4)$ & 0.986 & 0.000 \\
\hline Milk products & $283.4(166.4)$ & $332.1(246.9)$ & $335.0(298.3)$ & 0.377 & 0.009 \\
\hline Cereal products & $332.8(162.9)$ & $346.5(149.4)$ & $304.0(130.6)$ & 0.671 & 0.010 \\
\hline Coffee & $230.7(155.8)$ & $282.2(207.1)$ & $243.1(184.4)$ & 0.587 & 0.015 \\
\hline Tea & $118.3(147.0)$ & $97.1(155.6)$ & $149.6(187.0)$ & 0.698 & 0.014 \\
\hline Alcohol & $4.8(8.4)$ & $4.5(7.9)$ & $5.0(7.8)$ & 0.986 & 0.000 \\
\hline \multicolumn{6}{|l|}{ Energy, nutrients per day } \\
\hline Energy, kcal & $1512(278)$ & $1610(369)$ & $1641(439)$ & 0.166 & 0.017 \\
\hline $\begin{array}{l}\text { Protein, g } \\
\text { g/kg BW/day } \\
\text { Protein E\% }\end{array}$ & $\begin{array}{l}72(17) \\
0.93(0.24) \\
19\end{array}$ & $\begin{array}{l}74(23) \\
0.95(0.29) \\
18\end{array}$ & $\begin{array}{l}73(25) \\
1.00(0.36) \\
18\end{array}$ & $\begin{array}{l}0.792 \\
0.439 \\
0.167\end{array}$ & $\begin{array}{l}0.003 \\
0.006 \\
0.012\end{array}$ \\
\hline $\begin{array}{l}\text { Carbohydrates, g } \\
\text { Starch } \\
\text { Sugar } \\
\text { Fiber } \\
\text { Carbohydrate E\% }\end{array}$ & $\begin{array}{l}164(39) \\
82(27) \\
23(12) \\
22(7) \\
44\end{array}$ & $\begin{array}{l}168(40) \\
87(25) \\
23(11) \\
22(9) \\
42\end{array}$ & $\begin{array}{l}180(61) \\
86(26) \\
31(16) \\
21(9) \\
44\end{array}$ & $\begin{array}{l}0.241 \\
0.486 \\
0.050 \\
0.515 \\
0.854\end{array}$ & $\begin{array}{l}0.013 \\
0.008 \\
0.052 \\
0.004 \\
0.012\end{array}$ \\
\hline Fat, g & $59(17)$ & $67(22)$ & $66(22)$ & 0.139 & 0.030 \\
\hline SFA & $20(7)$ & $23(8)$ & $23(8)$ & 0.058 & 0.035 \\
\hline MUFA & $22(7)$ & $26(12)$ & 25 (12) & 0.174 & 0.023 \\
\hline PUFA & $12(5)$ & $13(5)$ & $11(5)$ & 0.786 & 0.012 \\
\hline Fat E\% & 35 & 37 & 36 & 0.279 & 0.026 \\
\hline
\end{tabular}

Data of continuous variables are mean (SD)

$S D$ standard deviation, MNA-SF Mini Nutritional Assessment Short Form, SPPB Short Physical Performance Battery, BMI Body Mass Index, Alm/ $\mathrm{m}^{2}$ appendicular lean mass/meter squared, SFA saturated fatty acids, MUFA monounsaturated fatty acids, $P U F A$ polyunsaturated fatty acids

${ }^{1}$ The statistical significance of the hypotheses of linearity was evaluated for a trend using ANOVA for continuous variables and Cochrane Armitage test for categorical variables, $p$ value $<0.05$ was taken as statistically significant; $\eta^{2}=$ strength of association

often believed that older people need less sleep than younger ones, a recent study of 40,000 participants suggested that the optimal amount of sleep was similar for all adult age groups. Sleep-related impairments of cognition also seemed to affect all ages equally [20].

Several theories on nutrition and sleep exist. It is, for example, suggested that specific protein-rich foods are particularly good for sleep, because they are sources of amino acid tryptophan-a precursor of sleep-inducing compounds serotonin and melatonin [21]. Furthermore, combining both carbohydrates and protein in the same meal makes tryptophan more available to the brain [22]. In one study, higher complex carbohydrates intake was associated with better sleep. High sugar intake, in turn, had an opposite effect, and was associated with more excessive daytime sleepiness [8]. In our study, the association between sugar intake and poor 
Table 2 Characteristics and nutrition intakes according to sleep time at night in oldest-old men

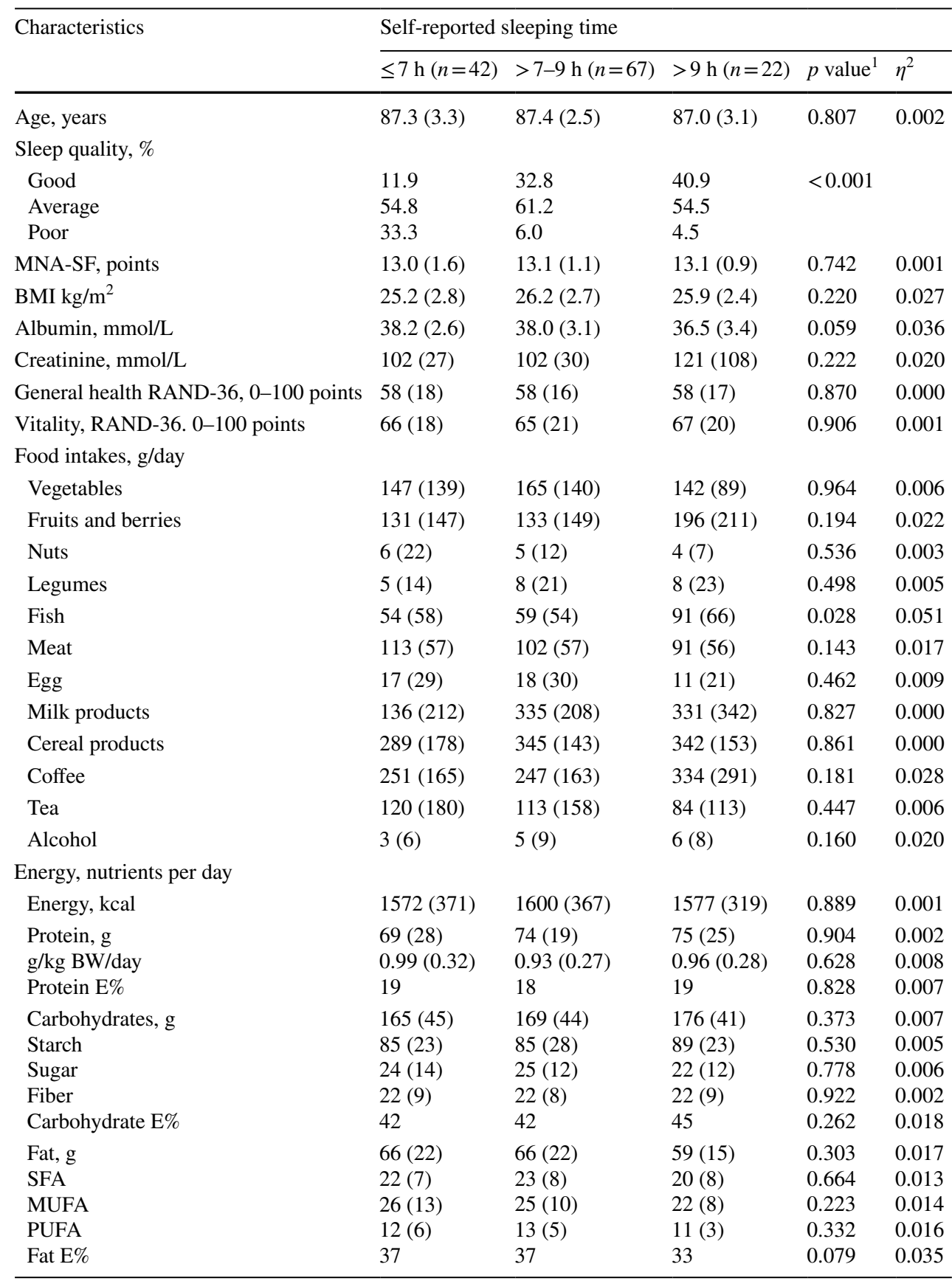

Data of continuous variables are mean (SD)

$S D$ Standard deviation, MNA-SF Mini Nutritional Assessment Short Form, BMI body mass index, kcal kilocalorie, $B W$ body weight, $k g$ kilo grams, $S F A$ saturated fatty acids, MUFA monounsaturated fatty acids, $P U F A$ polyunsaturated fatty acids

${ }^{1}$ The statistical significance of the hypotheses of linearity was evaluated for a trend using ANOVA for continuous variables and Cochran Armitage test for categorical variables, $p$ value $<0.05$ was taken as statistically significant; $\eta^{2}=$ strength of association sleep quality was of borderline significance only $(p=0.050)$, possibly due to insufficient statistical power. Interestingly, higher saturated fatty acid intake also tended to be associated with poor sleep quality $(p=0.058)$. Moreover, higher nutritional status and vegetable intake were associated with better sleep quality. These findings are in agreement with some earlier research where dietary patterns characterized with intake abundant of fruits and vegetables and legumes have been associated with better sleep quality and less sleep disturbances [5, 6] In addition, our finding on fish intake and 
Table 3 ANCOVA models 1 and 2 of associative factors of sleep duration at night time

\begin{tabular}{lrrrr}
\hline & $B$ & \multicolumn{2}{l}{$95 \%$ confidence interval } & \multirow{2}{*}{$p$ value } \\
& & Lower bound & Upper bound & \\
\hline Model 1 & & & & \\
Intercept & 6.504 & -1.247 & 14.255 & 0.099 \\
Age & -0.002 & -0.090 & 0.086 & 0.988 \\
Sleep quality; good vs. poor & 1.793 & 0.957 & 2.628 & $<0.001$ \\
Sleep quality; average vs. poor & 1.392 & 0.641 & 2.144 & $<0.001$ \\
Fish intake, g/day & 0.007 & 0.003 & 0.012 & 0.002 \\
Adjusted $R^{2}$ & $\mathbf{0 . 1 7 1}$ & & & $<0.001$ \\
Model 2 & & & & $<0.001$ \\
Intercept & 7.704 & 4.165 & 11.242 & $<0.001$ \\
Sleep quality; good vs. poor & 1.822 & 1.001 & 2.642 & 0.001 \\
Sleep quality; average vs. poor & 1.498 & 0.753 & 2.244 & 0.097 \\
Fish intake, g/day & 0.007 & 0.003 & 0.012 & 0.122 \\
Albumin, mmol/L & -0.071 & -0.155 & 0.013 & \\
Carbohydrate energy \% of total energy & 0.029 & -0.008 & 0.066 & \\
Adjusted $R^{2}$ & $\mathbf{0 . 1 9 7}$ & & & \\
\hline
\end{tabular}

Bold value indicates the amount of observed variation that can be explained by the model's inputs sleep is in agreement with a study reporting an association between higher fatty fish intake and better sleep quality in participants $>40$ years of age [7]. In the Hellenic Longitudinal Investigation of Aging and Diet Study, Mediterranean dietary pattern characterized by high fruit and vegetable, legume and fish intakes was also associated with better sleep quality in people $>75$ years of age [23].

The strengths of our study include robust main findings, despite the relatively small sample size, and the fact that to the best of our knowledge, this is the first study to explore the relationship between nutrition and sleep in oldest-old community-dwelling men. A limitation of our study is a crude measurement of sleep characteristics and that data from extensive sleep quality questionnaires or polysomnography were not available. Assessing food intake is challenging. Food diaries are one of the best ways to record food intake in older people. However, they may be affected by considerable under- or overreporting of the foods consumed, which may cause bias. However, every effort was made to ensure the correctness of the dietary records. The participants received written and oral advice beforehand on how to fill in the food records, and phone calls were made afterwards in order to confirm that the dietary information was reported as accurately as possible. Furthermore, the surviving participants of the Helsinki Businessmen Study differ in many ways from the general population thus limiting generalizability. The cross-sectional design of the study is also a limitation and prevents drawing conclusions about temporal relationships between nutritional factors and sleep.

In conclusion, sleep quality and quantity were associated with characteristics of a healthy dietary pattern in oldest-old men living in the community. These findings may extend current nutrition recommendations by emphasizing the importance of abundant intake of fruits and vegetables and regular fish intake for sleep [24].

Acknowledgements This work was supported by Foundation of Nutrition Research, VTR-funding of the Helsinki University Hospital (EVO), Helsinki University Hospital Internal Medicine and Rehabilitation and Academy of Finland, Grant number 311492, Nord Forsk and Helsinki Institute of Life Science. The sponsors did not have any role in the study design, analysis or interpretation of data, nor in writing the report or the decision to submit this article. The authors were independent researchers not associated with the funders.

Author contributions SKJ design, conceptualization, and performed the data-analysis, AU carried out the clinic visits. All authors contributed to writing of the manuscript and approved the final version.

Funding Open access funding provided by University of Helsinki including Helsinki University Central Hospital.

\section{Compliance with ethical standards}

Conflict of interest SKJ: reports no conflict of interest. AU: reports no conflict of interest. MK: reports grants from Nord Forsk, the Academy of Finland, and Helsinki Institute of Life Science, during the conduct of the study. TES: reports having various educational and consultative cooperation with several companies, including Nutricia, Abbott, Amgen, Merck, Pfizer, Novartis, and Novo-Nordisk; a minor amount of stock in Orion Pharma; and is a board member and former president of executive board of European Union Geriatric Medicine Society which has cooperation also with the nutrition industry.

Ethical approval The study protocol was approved by the Ethics Committee of the Helsinki University Hospital, Department of Medicine. The study is registered with ClinicalTrials.gov identifier: NCT02526082. 
Informed consent All participants signed an informed consent.

Open Access This article is licensed under a Creative Commons Attribution 4.0 International License, which permits use, sharing, adaptation, distribution and reproduction in any medium or format, as long as you give appropriate credit to the original author(s) and the source, provide a link to the Creative Commons licence, and indicate if changes were made. The images or other third party material in this article are included in the article's Creative Commons licence, unless indicated otherwise in a credit line to the material. If material is not included in the article's Creative Commons licence and your intended use is not permitted by statutory regulation or exceeds the permitted use, you will need to obtain permission directly from the copyright holder. To view a copy of this licence, visit http://creativecommons.org/licenses/by/4.0/.

\section{References}

1. Watson NF, Badr MS, Belenky G, Bliwise DL, Buxton OM, Buysse D et al (2015a) Joint Consensus Statement of the American Academy of Sleep Medicine and Sleep Research Society on the recommended amount of sleep for a healthy adult: methodology and discussion. Sleep 38:1161-1183

2. Watson NF, Badr MS, Belenky G, Bliwise DL, Buxton OM, Buysse D et al (2015b) Recommended amount of sleep for a healthy adult: a joint consensus statement of the American Academy of Sleep Medicine and Sleep Research Society. Sleep 38:843-844

3. Mander BA, Winer JR, Walker MP (2017) Sleep and human aging. Neuron 94:19-36

4. Lin HH, Tsai PS, Fang SC, Liu JF (2011) Effect of kiwifruit consumption on sleep quality in adults with sleep problems. Asia Pac J Clin Nutr 20:169-174

5. Kurotani K, Kochi T, Narni A, Eguchi M, Kuwahara K, Tsuruoka $\mathrm{H}$ et al (2015) Dietary patterns and sleep symptoms in Japanese workers: the Furukawa Nutrition and Health Study. Sleep Med 2:298-304

6. Cao Y, Taylor AW, Wittert G, Adams R, Shi Z (2017) Dietary patterns and sleep parameters in a cohort of community dwelling Australian men. Asia Pac J Clin Nutr 26:1158-1169

7. del Brutto OH, Mera RM, Ha J, Gillman J, Zambrano M, Castillo PR (2016) Dietary fish intake and sleep quality: a populationbased study. Sleep Med 17:126-128

8. Grandner MA, Jackson N, Gerstner JR, Knutson KL (2014) Sleep symptoms associated with intake of specific dietary nutrients. J Sleep Res 23:22-34

9. Pigeon WR, Carr M, Gorman C, Perlis ML (2010) Effects of a tart cherry juice beverage on the sleep of older adults with insomnia: a pilot study. J Med Food 13:579-583

10. Yamamoto K, Motokawa K, Yoshizaki T, Yano T, Hirano H, Ohara Y et al (2020) Association of dietary variety and appetite with sleep quality in urban-dwelling older Japanese adults. J Nutr Health Aging 24:152-159

11. Huang YC, Wahlqvist ML, Lee MS (2013) Sleep quality in the survival of elderly Taiwanese: roles for dietary diversity and pyridoxine in men and women. J Am Coll Nutr 32:417-427

12. Štefan L, Radman I, Podnar H, Vrgoč G (2018) Sleep duration and sleep quality associated with dietary index in free-living very old adults. Nutrients 10:1748

13. Strandberg TE, Salomaa V, Strandberg AY, Vanhanen H, Sarna S, Pitkälä K et al (2016) Cohort profile: the Helsinki Businessmen Study (HBS). Int J Epidemiol 45:1074-1074h

14. Vellas B, Guigoz Y, Garry PJ, Nourhashemi F, Bennahum D, Launque S, Albarede JL (1999) The Mini Nutritional Assessment (MNA) and its use in grading the nutritional state of elderly patients. Nutrition 15:116-122

15. Hays RD, Morales LS (2001) The RAND-36 measure of healthrelated quality of life. Ann Med 33:350-357

16. Aalto A-M, Aro AR, Teperi J (1999) RAND-36 Terveyteen liittyvän elämänlaadun mittarina - Mittarin luotettavuus ja suomalaiset väestöarvot, Stakes Sosiaali- ja terveysalan tutkimus- ja kehittämiskeskus 101 (in Finnish)

17. Lindseth G, Murray A (2016) Dietary macronutrients and sleep. West J Nurs Res 38:938-958

18. Bharadwaj S, Ginoya S, Tandon P, Gohel TD, Guirguis J, Vallabh $\mathrm{H}$ et al (2016) Malnutrition: laboratory markers vs nutritional assessment. Gastroenterol Rep (Oxf) 4:272-280

19. Daghlar I, Dashti HS, Lane J, Aragam KG, Rutter MK, Saxena R et al (2019) Sleep duration and myocardial infarction. J Am Col Card 10:1315-1316

20. Wild CJ, Nichols ES, Battista ME, Stojanoski B, Owen AM (2018) Dissociable effects of self-reported daily sleep duration on high-level cognitive abilities. Sleep 12:182

21. Friedman M, Levin CE (2012) Nutritional and medicinal aspects of D-amino acids. Amino Acids 42:1553-1582

22. Wurtman RJ, Wurtman JJ, Regan MM, McDermott JM, Tsay RH, Breu JJ (2003) Effects of normal meals rich in carbohydrates or proteins on plasma tryptophan and tyrosine ratios. Am J Clin Nutr 77:128-132

23. Mamalaki E, Anastasiou CA, Ntanasi E, Tsapanou A, Kosmidis MH, Dardiotis E et al (2018) Associations between the mediterranean diet and sleep in older adults: results from the hellenic longitudinal investigation of aging and diet study. Geriatr Gerontol Int 18:1543-1548

24. Nordic Nutrition Recommendations: Integrating nutrition and physical activity. Nordic Council Ministers 2014. Copenhagen. Internet: 10.6027/Nord 2014-002. Accessed 23 Mar 2020.

Publisher's Note Springer Nature remains neutral with regard to jurisdictional claims in published maps and institutional affiliations. 